\title{
HUBUNGAN ANTARA MODAL SOSIAL DAN RESPONS MASYARAKAT DENGAN PERSEPSI EFEKTIFITAS KELEMBAGAAN PENGELOLAAN PERIKANAN DI WADUK MALAHAYU, JAWA TENGAH
}

\author{
Tajerin, Risna Yusuf, Tikkyrino Kurniawan dan Zahri Nasution \\ Balai Besar Penelitian Sosial Ekonomi Kelautan dan Perikanan \\ JI. KS. Tubun Petamburan VI Jakarta 10260 \\ Telp. (021) 53650162, Fax. (021)53650159 \\ Diterima 28 Februari 2012 - Disetujui 4 Juni 2012
}

\begin{abstract}
ABSTRAK
Penelitian ini dilakukan untuk melihat hubungan antara modal sosial dan respons masyarakat dengan persepsi efektifitas kelembagaan pengelolaan perikanan di Waduk Malahayu di Kabupaten Brebes, Jawa Tengah. Metode penelitian menggunakan metode survei. Pengambilan responden dilakukan secara proportional random sampling. Analisis data dilakukan secara deskriptif serta diuji dengan pendekatan non parametrik Uji Perbedaan Mann-Whitnet-U dan Uji Korelasi Pearson's Product Moment. Hasil penelitian menunjukkan bahwa terdapat perbedaan yang nyata dalam perubahan efektifitas kelembagaan antara sebelum dan setelah program penguatan kapasitas masyarakat. Hal ini mengindikasikan penguatan kapasitas masyarakat memiliki peran yang positif dan nyata terhadap perubahan efektifitas kelembagaan pengelolaan perikanan Waduk Malahayu yang meningkat. Respons masyarakat mengenai penguatan kapasitas berhubungan positif dan nyata dengan perubahan efektifitas kelembagaan yang dimediasi modal sosial masyarakat, terutama yang didorong oleh perasaan saling mempercayai dan rasa aman, toleransi dan kebhinekaan, dan nilai hidup dan kehidupan. Kecenderungan ini menunjukkan pentingnya memupuk perasaan saling mempercayai dan rasa aman, toleransi dan kebhinekaan, dan nilai hidup dan kehidupan sebagai bagian dari upaya rekayasa sosial, khususnya dalam meningkatkan efektifitas kelembagaan pengelolaan perikanan waduk yang memberikan jaminan keberlanjutannya.
\end{abstract}

Kata kunci: modal sosial, respons, efektifitas kelembagaan, perairan waduk

\section{Abstract : The Relationship Between Social Capital and Community Respons with Perception of Fishereis Management Institutions Efectiveness in Malahayu Reservoir, Central Java. By : Tajerin, Risna Yusuf, Tikkyrino Kurniawan and Zahri Nasution.}

Research looked at the relationship between social capital and community response to the perception of the effectiveness of institutional management of fisheries in the reservoir Malahayu, Brebes, Central Java. The method used by survey method. Respondents selected by proportional random sampling. The data were analyzed by descriptively and tested with a non paramterik difference Test Mann-Whitnet- $U$ and Pearson's Product Moment Correlation test. The results showed that there were significant differences in the effectiveness of institutional change between before and after a community capacity building program. This indicates a strengthening of the capacity of the community has a positive and a real role to change the institutional effectiveness of reservoir fisheries management Malahayu increased. The response of the public on capacity building and real positively associated with changes in institutional effectiveness dimedasi social capital, primarily driven by a sense of trust and security, tolerance and diversity, and the value of life and living. This trend shows the importance of a sense of trust and security, tolerance and diversity, and the value of life and living as part of the social engineering efforts, especially in increasing the effectiveness of reservoir fisheries management institutions to guarantee its sustainability.

Keywords: social capital, response, institutional effectiveness, reservoir fisheries 


\section{PENDAHULUAN}

Berbagai program pembangunan di berbagai sektor termasuk perikanan, disinyalir banyak mengalami kegagalan terutama karena kekurang-efektifan kelembagaan yang ada (Satria, 2009). Dukungan kelembagaan yang kurang memadai, bahkan terkesan sekedar memenuhi persyaratan dilaksanakannya suatu program pembangunan perikanan, menjadi faktor dominan yang menyebabkan kegagalan dari program-program tersebut.

Ke-tidak-efektif-an program pembangunan di berbagai sektor termasuk perikanan diduga karena kurang memperhatikan kondisi sosial ekonomi dan budaya termasuk respons dan modal sosial dari masyarakat nelayan yang menjadi sasarannya. Respons masyarakat mengenai suatu program pembangunan perikanan, misalnya, dapat menjadi indikator dan penentu efektifitas dari program tersebut (sebagai suatu stimulus) di tingkat implementasi, sedangkan modal sosial dapat menjadi faktor yang turut melatar-belakangi (mediator) bagaimana repons mengenai suatu program tersebut terjadi dalam realitas dan menentukan ke-efektif-an program yang dilakukan. Respons dikatakan Darly Beum sebagai tingkah laku balas atau sikap yang menjadi tingkah laku yang memadai atau sesaui harapan (adecuate behavioral); dan Scheerer menyebutkan respons merupakan proses pengorganisasian rangsang dimana rangsang-rangsang prosikmal diorganisasikan sedemikian rupa sehingga terjadi representasi fenomenal dari rangsang (stimulus) prosikmal (Embretson and Rerise, 2000). Dalam teori rangsang balas (stimulus respon theory), kecenderungan atau kesediaan seseorang untuk bertingkah laku (bersikap) tertentu kalau ia mengalami rangsang (stimulus) tertentu. Sikap ini terjadi biasanya terhadap benda, orang, kelompok, nilai-nilai dan semua hal yang terdapat di sekitar manusia (Fitts and Deininger, 2004; Proctor and Reeve, 2009).
Sementara, modal sosial (social capital) secara sederhana bisa didefinisikan sebagai serangkaian nilai-nilai atau normanorma informal yang dimiliki bersama diantara para anggota suatu kelompok yang memungkinkan terjadinya kerjasama diantara mereka (Fukuyama, 2002). Selanjutnya, Collen dan Whiteford (2001) diacu dalam Hasbullah (2006) memberikan pengertiaan bahwa modal sosial sebagai stok dari hubungan yang aktif antar masyarakat. Setiap pola hubungan yang terjadi diikat oleh kepercayaan (trust), kesaling-pengertian (mutual understanding) dan nilai-nilai bersama (shared value) yang mengikat anggota kelompok untuk membuat kemungkinan aksi (respons) bersama yang dapat dilakukan secara efisien dan efektif. Bank Dunia (1999) dalam Hasbullah (2006) mendefenisikan modal sosial sebagai sesuatu yang merujuk ke dimensi institusional (kelembagaan), hubunganhubungan yang tercipta dan norma-norma yang membentuk kualitas dan kuantitas hubungan sosial dalam masyarakat.

Secara empiris, modal sosial akan sangat mempengaruhi kedinamikaan suatu kelompok masyarakat atau keloembagaan yang berjalan secara efisien dan efektif, namun modal sosial memiliki makna bukan hanya sekedar deretan jumlah institusi atau kelembagaan yang menopang (underpinning) kehidupan sosial, melainkan dengan spektrum yang lebih luas, yaitu sebagai perekat sosial (social glue) yang mampu menjaga kesatuan anggota kelompok secara bersama-sama. Dengan demikian peran respons dan modal sosial masyarakat menjadi sangat penting tatkala sebuah kelembagaan mulai dipertanyakan tingkat efektifitasnya. Dengan respons dan modal sosial masyarakat yang baik, sebuah kelembagaan akan mengalami kedinamikaan yang tinggi dan pada gilirannya akan mendorong perubahan efektifitas kelembagaan menjadi lebih baik dibandingkan bila respons dan modal sosial yang ada tergolong buruk. 
Kesadaran para pemangku kepentingan (stakeholders) terutama para pembuat kebijakan (policy making) maupun para penerima program (users) terhadap pentingnya keefektifitif-an kelembagaan dalam mendukung berbagai program pembangunan perikanan berkelanjutan sangat diharapkan, seperti pada program peningkatan kapasitas masyarakat nelayan di sekitar Waduk Malahayu, Kabupaten Brebes, Jawa Tengah. Di sisi lain, program tersebut harus berjalan secara berkelanjutan sehingga diperlukan sebuah sistem kelembagaan yang baik (efektif) untuk memberikan jaminan bagi keberlanjutan upaya pengelolaan sumber daya di suatu perairan (Ostrom, 1990) yang dilakukan untuk memenuhi kebutuhan saat ini, tanpa mengorbankan kemampuan generasi mendatang untuk dapat memenuhi kebutuhannya (WCED, 1988).

Tulisan ini disusun dengan tujuan untuk mengetahui hubungan antara modal sosial dan respons masyarakat dengan persepsi efektifitas kelembagaan pengelolaan perikanan di Waduk Malahayu, Kabupaten Brebes, Provinsi Jawa Tengah.

\section{METODOLOGI}

\section{Lokasi dan Waktu Penelitian}

Penelitian dilakukan pada komunitas masyarakat nelayan yang di Dukuh/ kampung Rembet, Karacak, Dukuh jati, Cawiri dan Balsiah-Malahayu dimana semua dukuh/kampung ini berada di sekitar perairan Waduk Malahayu, Kabupaten Brebes, Jawa Tengah. Penelitian berlangsung sejak bulan Mei hingga Desember 2011.

\section{Jenis dan Sumber Data serta Penentuan Responden}

Data yang digunakan dalam penelitian ini merupakan data primer yang diperoleh dari hasil wawancara dengan nelayan responden dengan menggunakan bantuan kuesioner. Jenis data tersebut adalah data mengenai modal sosial yang dilihat dari indikator
(1) Partisipasi sosial masayarakat di dalam komunitas, (2) Tingkat resiprositas dan proaktivitas di dalam kegiatan sosial, (3) Perasaan saling mempercayai dan rasa aman, (4) Jaringan/ koneksi dalam komunitas, (5) Jaringan dan koneksi antar teman dan keluarga, (6) Toleransi dan kebhinekaan, (7) Jaringan/koneksi di luar komunitas, (8) Nilai hidup dan kehidupan, (9) Partisipasi dan keanggotaan kelompok di luar Komunitas. Sedangkan data mengenai respons masyarakat dalam kajian ini adalah pendapat atau tanggapan masyarakat nelayan terhadap hal-hal yang berkaitan dengan inovasi kelembagaan yang telah dilakukan melalui pemberian materi pelatihan sebagai upaya untuk memperkuat kelembagaan.

Responden dalam penelitian ini adalah nelayan sebanyak 30 orang yang ditentukan secara proportional random sampling dari setiap dukuh/kampung yang ada di sekitar perairan waduk tersebut. Pemilihan metode ini didasarkan pada tujuan untuk mencapai keterwakilan masing-masing kelompok sampel dan tingkat acak pada pengambilan data, dimana masing-masing kelompok sampel dipilih secara random sesuai dengan proporsinya (Juanda, 2009).

\section{Metode Analisis data}

Dalam penelitian ini digunakan pula dua analisis dengan pendekatan non-parametrik, yaitu Uji Perbedaan Mann-Whitney-U dan Uji Korelasi Pearson's Product Moment (PPM) yang masing-masing dijelaskan sebagai berikut (Siegel, 1998; Sprent and Smeecon, 2001):

1. Uji Perbedaan Mann-Whitney-U untuk melihat perbedaan antara efektifitas kelembagaan pengelolaan perikanan waduk sebelum dan setelah penguatan kapasitas masyarakat. Jenis kelembagaan yang diuji adalah (a) kelembagaan pelaku utama, (b) kelembagaan saprokan, (c) kelembagaan penyuluhan, (d) kelembagaan konservasi, (e) kelembagaan pengawasan, (f) kelembagaan pemasaran, dan (g) kelembagaan monev. Uji ini pada prinsipnya menguji hipotesis nol bahwa 
tidak ada perbedaan rata-rata ranking skor efektifitas kelembagaan pengelolaan perikanan waduk antara sebelum dan setelah penguatan kapasitas masyarakat.

2. Uji Korelasi Pearson's Product Moment (PPM) untuk melihat hubungan antara dua peubah yang dianalisis dengan formula sebagai berikut:

$$
r=\frac{S_{x y}}{\sqrt{S_{x x} S_{x y}}}
$$

dimana: $S_{x x}=\sum\left(x_{i}-\bar{x}\right)^{2} ; S_{x y}=\sum\left(y_{i}-\bar{y}\right)^{2} ;$ dan $S_{y y}=\sum\left(x_{i}-\bar{x}\right)\left(y_{i}-\bar{y}\right)$

PPM ini juga menyediakan statistik uji untuk hipotesis nol bahwa tidak ada hubungan antara dua peubah yang diteliti. Dalam penelitian ini, uji korelasi tersebut digunakan untuk melihat hubungan antara dua peubah dalam dua tahap. Pertama, menguji hubungan antara peubah respons mengenai penguatan kapasitas masyarakat (SEP) dengan peubah perubahan efektifitas kelembagaan pengelolaan perikanan waduk

(PEK); dan menguji hubungan antara peubah respons mengenai penguatan kapasitas masyarakat (SEP) dengan peubah modal sosial masyarakat (MDM); serta menguji hubungan antara peubah modal sosial masyarakat (MDM) dengan peubah perubahan efektifitas kelembagaan pengelolaan perikanan waduk (PEK).

Kedua, menguji hubungan antara SEP dan KEP dengan masing-masing indikator dari modal sosial yang diperlakukan sebagai peubah, yakni: partisipasi sosial masyarakat di dalam komunitas (MDM1), tingkat reprositas dan proaktivitas di dalam kegiatan sosial (MDM2), perasaan saling mempercayaai dan rasa aman (MDM3), jaringan dan koneksi di dalam komunitas (MDM4), jaringan dan koneksi antar teman dan keluarga (MDM5), toleransi dan kebhinekaan (MDM6), jaringan/koneksi di luar komunitas (MDM7), nilai hidup dan kehidupan (MDM8) dan partisipasi sosial masyarakat di luar komunitas (MDM9) (Kemalasari. 2005; Lenggono, 2004).

\section{HASIL DAN PEMBAHASAN}

\section{Penguatan Kapasitas dan Respons Masyatakat}

Penguatan kapasitas masyarakat nelayan yang dimaksudkan dalam penelitian ini adalah merupakan bagian dari upaya pengembangan kelembagaan pengelolaan perikanan di Waduk Malahayu, Jawa Tengah yang didasarkan pada pertimbangan untuk memperbaiki dimansi aturan main kelembagaan yang mengalami pelemahan. Penguatan tersebut dimplementasikan dalam bentuk pelatihan dan pendampingan kepada masyarakat nelayan di sekitar Waduk Malahayu, Jawa Tengah. Adapun materi kegiatan pelatihan dan pendampingan tersebut adalah seperti tertera pada Tabel 1.

Materi yang bersifat teknis, seperti tata cara pembukuan usaha dan kelompok (organisasi) dan penguasaan teknologi pembenihan ikan patin secara nyata di lapangan dalam jangka waktu sesuai dengan periode pembenihan ikan patin atau mulai dari penangnanan induk ikan, pemijahan hingga penetasan dan pemanenan benih ikan patin. Di samping itu, dalam pendampingan juga dilakukan kegiatan pengembangan kelompok nelayan, inisiasi dan pembentukan kelembagaan Kelompok Usaha Bersama (KUB) dan Koperasi Serba Usaha (KSU) nelayan Waduk Malahayu.

Respons masyarakat nelayan yang dimaksudkan dalam penelitian ini adalah pendapat atau tanggapan masyarakat nelayan terhadap hal-hal yang berkaitan dengan materi program penguatan kapasitas masyarakat yang diterimanya melalui kegiatan pelatihan dan penampingan. Adapun respons masyarakat mengenai keseluruhan materi pelatihan dan pendampingan tersebut secara rinci tertera pada Tabel 2. 
Tabel 1. Materi Pelatihan dan Pendampingan dalam Program Penguatan Kapasitas Masyarakat di Waduk Malahayu, Jawa Tengah, 2011 ${ }^{1}$.

Table 1. Topics of Training and Assistance on Community Capacity Building, Malahayu Reservoir, Central Java, $2011^{1}$.

\section{No. Materi Pelatihan dan Pendampingan/Topics of Training and Asisstance}

Pengetahuan organisasi dan pengembangan usaha/ Organization and business

1. development knowledge

1.1 Manfaat berorganisasi dan koperasi/Benefit of organization and cooperative

1.2 Tata cara pembukuan/penyusunan neraca keuangan/ Accounting procedures

1.3 Teknik penyusunan proposal untuk memperoleh kredit perbankan/How to make a loan proposal

1.4 Analisis usaha pembesaran ikan patin/ Catfish growin'sg business analysis

1.5 Akses permodalan usaha/Access to business capital

1.6 Mekanisme pembentukan KUB dan Koperasi/ Establishment of KUB and cooperative mechanism

1.7 Kewirausahaan masyarakat nelayan/ Interpreneurship of fisherman community

2. Penguasaan Teknologi Pembenihan Ikan Patin/Mastership of catfish hachery

2.1 Teknik pembenihan ikan patin secara umum/ Catfish hacthery technique

2.2 Teknologi seleksi induk matang gonad dan penyuntikan induk ikan patin/ Technology selection of mature parent gonad and injection of catfish parent

2.3 Teknologi penetasan cyste artemia secara umum/Technology of incubation of cyste artemia

2.4 Teknologi pemijahan buatan dan penetasan telur/Technology of artificial spawning and hatching of eggs

2.5 Teknologi pemanenan dan pemberian pakan artemia/Technology of harvest and giving feed artemia

2.6 Teknologi pemanenan dan penebaran larva/Technology of harvest and larval stocking

2.7 Teknologi Penetasan cyste artemia lanjutan/Technology of cyste artemia incubation

Tabel 2. Sebaran Kategori Respons Masyarakat mengenai Penguatan Kapasiatas Masyarakat terkait dengan Peningkatan Efektifitas Kelembagaan Pengelolaan Waduk Malahayu, 2011.

Table 2. Categories of Community Respons Capacity Building Related to Increasing Effectiveness Institutional Management, Reservoir Malahayu, 2011.

\begin{tabular}{lccc}
\hline \multicolumn{1}{c}{ Kategori/Categories } & $\begin{array}{l}\text { Interval Skor/ } \\
\text { Score Interval }\end{array}$ & $\begin{array}{c}\text { Jumlah (Orang)/ } \\
\text { Amount (Person) }\end{array}$ & (\%) \\
\hline - $\begin{array}{l}\text { Kurang baik (kurang positif) / } \\
\begin{array}{l}\text { Deficient } \\
\text { Cukup Baik }\end{array}\end{array}$ & $62.00-103.33$ & 9 & 30.00 \\
$\begin{array}{l}\text { (cukup pistif)/Sufficient } \\
\text { Baik (positif)/Good }\end{array}$ & $103.34-144.67$ & 21 & 70.00 \\
\hline \multicolumn{1}{r}{ Keseluruhan/Total } & $144.68-186.00$ & 0 & 0.00 \\
\hline
\end{tabular}

Sumber: Data Primer diolah, 2011/Source: primary data processed, 2011

${ }^{1}$ Materi pelatihan dan pendampingan disusun berdasarkan hasil assessment kebutuhan masyarakat dan diagnosa indikator efektifitas kelembagaan masyarakat nelayan yang membutuhkan penguatan dalam rangka pengelolaan Waduk Malahayu, Brebes tahun 2011. 
Dalam prakteknya, materi penguatan kapasitas tersebut meliputi materi pengembangan organisasi dan materi pengembangan usaha. Secara keseluruhan dari kedua materi tersebut, respons masyarakat nelayan mengenai penguatan kapasitas masyarakat terkait dengan peningkatan efektifitas kelembagaan pengelolaan perikanan Waduk Malahayu, Jawa Tengah didominasi oleh kategori respons yang cukup positif (70\%), sisanya sebanyak $30 \%$ termasuk dalam kategori respons yang kurang positif. Atau secara rata-rata respons masyarakat mengenai penguatan kapasitas masyartakat tersebut termasuk dalam kategori cukup baik (cukup positif). Dengan adanya respons yang cukup baik terhadap materi penguatan kapasitas kelembagaan ini diharapkan inovasi penguatan kelembagaan tersebut dapat meningkatkan kapasitas masyarakat dalam rangka peningkatan efektifitas kelembagaan pengelolaan Waduk Malahayu pengelolaan sumberdaya perikanan di perairan Waduk Malahayu, Kabupaten Brebes, Jawa Tengah.

Bila diperhatikan menurut jenis materi penguatan kapasitas yang diberikan diterima masyarakat melalui kegiatan pelatihan dan pendampingan, tampak bahwa masyarakat nelayan di Waduk Malahayu cenderung lebih merespon secara positif terhadap materi pengembangan usaha dibandingkan materi pengembangan organisasi. Dari kedua materi tersebut, respons masyarakat nelayan terhadap materi pengembangan usaha perikanan baik pada level pemahaman maupun manfaatnya secara relatif lebih baik dibandingkan dengan materi pengembangan organisasi (Gambar 1).

Dari aspek rasionalitas, hal ini dapat diterima karena untuk kondisi sosial ekonomi yang ada seperti saat dilakukan pengamatan dimana berdasarkan hasil survei yang telah dilakukan dimana rata-rata pendapatan mereka masih kurang Rp. 700.000,- per bulan yang menurut batasan tingkat kemiskinan versi BPS, 2006 dimana angka tersebut tergolong pada kondisi yang lemah (miskin). Dengan rata-rata pendapatan tersebut, maka mereka akan lebih memperhatikan pentingnya perbaikan kondisi usaha secara langsung dibandingkan pengembangan organisasi kelompok nelayan yang ada. Namun jika dilihat lebih lanjut, aspek pemahaman dan manfaat yang diperoleh dari materi pengembangan usaha direspon secara positif (tinggi dan relatif sama oleh masyarakat nelayan).

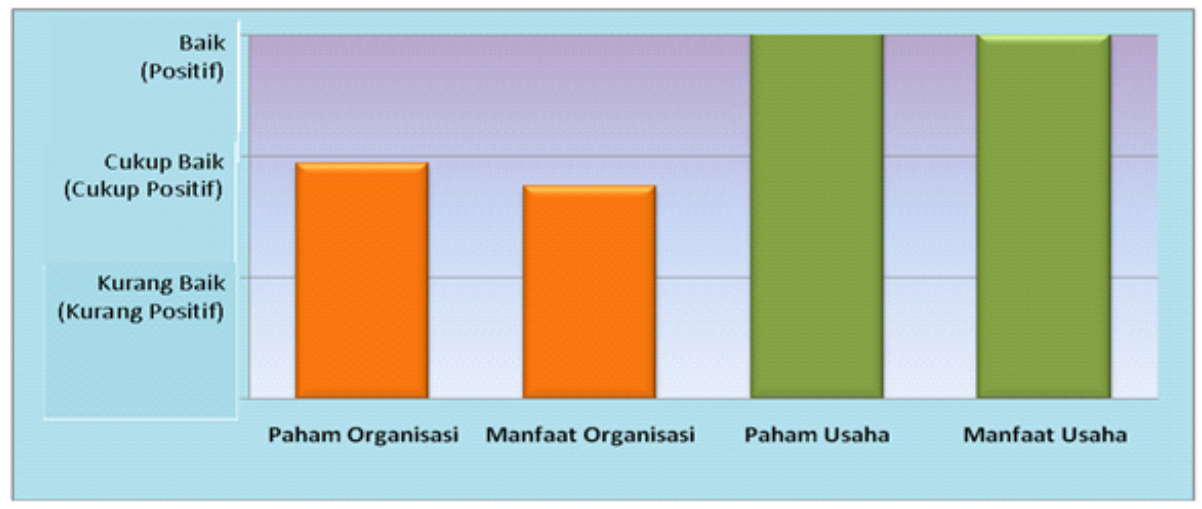

Gambar 1. Respons Masyarakat Nelayan mengenai Pemahaman dan Manfaat dari Pengembangan Organsiasi dan Usaha dalam Rangka Penguatan Kapasitas Masyakarat di Waduk Malahayu, 2011.

Figure 1. Fisherman Community Respons About Understanding and Beneficial Organization and Business Development in Order to Capacity Building of Community in Malahayu Reservoir, 2011. 
Hal ini mengindikasikan bahwa mereka dapat memahami dan menyadari manfaat materi pengembangan usaha tersebut secara baik (positif) Sementara terhadap aspek pemahaman dan manfaat materi pengembangan organisasi mendapatkan respons yaog berbeda oleh masyarakat nelayan di Waduk Malahayu. Masyarakat nelayan tersebut memberikan respon yang lebih relatif mendekati baik (mendekati positif) mengenai aspek pemahaman dari pengembangan organisasi dibanding dengan aspek manfaat pengembangan organisasi yang lebih tergolong sebagai cukup baik (cukup positif). Kecenderungan ini menunjukkan bahwa menurut respon yang diberikan oleh masyarakat nelayan di Waduk Malahayu, manfaat dari materi pengembangan organisasi diperkirakan oleh mereka belum secara nyata dalam waktu dekat dibandingkan dengan aspek pemahaman dari materi tersebut.

Selanjutnya, secara keseluruhan dari enam aspek penerapan teknologi perbenihan ikan patin di sekitar Waduk Malahayu direspon secara berbeda oleh masyarakat nelayan, secara rinci hal ini dapat dilihat pada Gambar 2.

Untuk aspek pemahaman teknologi dan keuntungan dari penerapan teknologi mendapat respon yang lebih positif dibandingkan dengan empat aspek lainnya (penerapan teknologi, kerumitan teknologi, ketersediaan sarana prasarana, dan kecepatan memperoleh hasil). Bila dilihat lebih lanjut dari Gambar 2, dapat diketahui bahwa terdapat kecenderungan respons masyakat nelayan termasuk kurang baik (kurang positif) terhadap aspek ketersediaan sarana prasana teknologi (Sarprastek) pembenihan ikan patin) dibandingkan dengan aspek lainnya dari materi penguasaan teknologi pembenihan ikan patin. Diduga hal ini karena faktor kesulitan yang dihadapi oleh masyarakat untuk melaksanakan teknologi pembenihan ikan patin sesuai dengan anjuran yang diterima dalam pelatihan dan pendampingan. Untuk dapat menjalankan kegiatan pembenihan ikan patin secara baik dibutuhkan fasilitas yang memadai dan harus memenuhi persyaratan tertentu. Hal teoritis, semestinya hal tersebut dapat mereka laksanakan dengan menggunakan fasilitas BBI yang ada, namun tetap saja sulit untuk mereka dapatkan secara baik, karena fasilitas BBI tersebut masih sangat terbatas dan kurang memadai, sehingga menjadi kurang optimal untuk menunjang keberhasilan penerapan teknologi perbenihan patin tersebut.

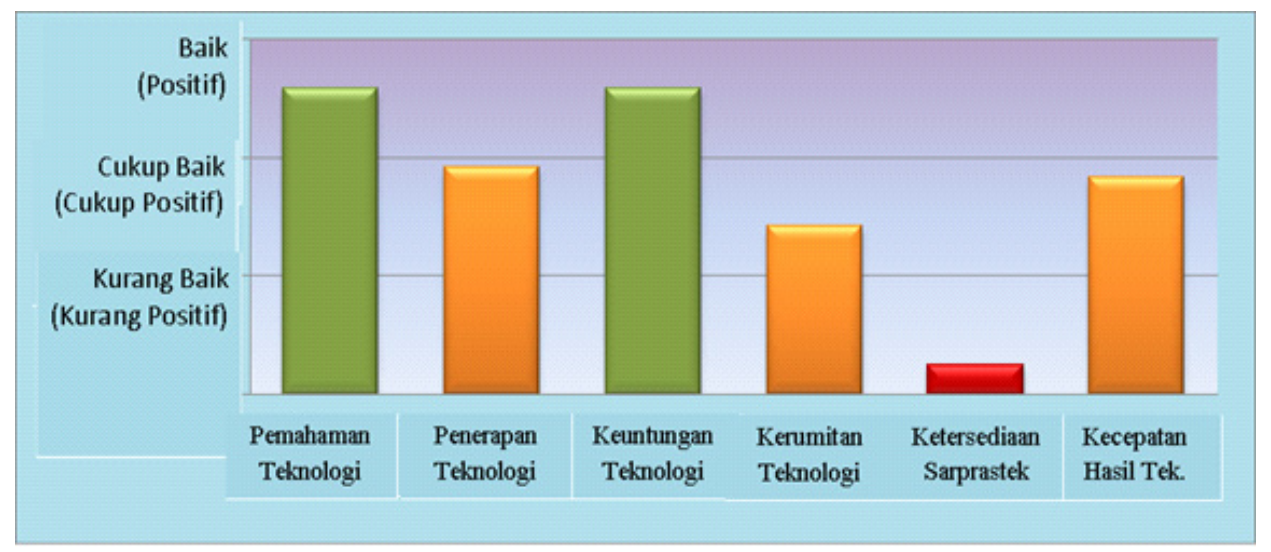

Gambar 2. Respon Masyarakat Nelayan Mengenai Materi Penguasaan Teknologi Pembenihan Ikan Patin dalam Rangka Penguatan Kapasitas Masyarakat di Sekitar Waduk Malahayu, 2011.

Figure 2. Fisherman Community Respons About Topics of Hacthery Technology of Catfish in Order to Community Capacity Building in Malahayu Reservoir, 2011. 


\section{Karakteristik Modal Sosial Masyarakat Nelayan}

Dalam penelitian ini pengukuran peubah modal sosial masyarakat nelayan (MDM) merupakan skor komposit dari keseluruhan indikator dari modal sosial. Berdasarkan angka komposit skor modal sosial, diketahui bahwa modal sosial masyarakat nela yan di sekitar Waduk Malahayu, Jawa Tengah tergolong dalam kategori sedang (lihat Tabel 1). Kondisi ini menunjukkan bahwa modal sosial pada masyarakat tersebut tergolong cukup baik dan berpotensi untuk dijadikan sebagai modal mereka untuk meningkatkan nilai-nilai sosial dan ekonomi dalam kehidupannya ke depan. Secara empiris hal ini telah cukup banyak dibuktikan, seperti dari hasil peneltian yang dilakukan oleh Kemalasari (2005) yang menemukan bahwa melalui peran modal sosial dapat meningkatkan kesejahteraan rumahtangga nelayan migran di Desa Panimbang, Kecamatan Panimbang, Kabupaten Pandeglang, Provinsi Banten; dan peneltian Cullen dan Whiteford (2001) dengan mengambil lokasi kasus pada beberapa perdesaan di Australia menemukan bahwa terdapat hubungan yang positif dan nyata antara semakin tinggi modal sosial dengan derajat kesehatan dan kesehatan mental masyarakat; serta peneltian Lenggono (2004) yang mengambil kasus pada komunitas petambak di Desa Muara Pantuan, Kecamatan Anggana, Kabupaten Kutai Kertanegara menemukan bahwa melalui peningkatan modal sosial dalam pengelolaan waduk telah mampu mendorong mereka untuk menngkatkan kinerja produktivitas usaha dan pendapatannya.

Selanjutnya, dari Tabel 3 pula dapat diketahui bahwa berdasarkan indikatornya, modal sosial tergolong tinggi pada dua indikator, yaitu (1) Jaringan dan koneksi antar teman dan keluarga; dan (2) Nilai hidup dan kehidupan. Tingginya modal sosial pada kedua indikator tersebut menunjukkan bahwa masyarakat nelayan di sekitar perairan Waduk Malahayu tersebut dalam kehidupan sehari-harinya sangat menghargai manfaat jaringan dan koneksi antar teman dan keluarga, dan demikian pula halnya dengan nilai-nilai hidup dan kehidupan yang sangat dijunjung tinggi pada pada masyarakat tersebut.

Selain dari indikator jaringan dan koneksi antar teman dan keluarga, dan indikator niolai hidup dan kehidupan, modal sosial pada tujuh indikator lainnya tergolong dalam kategori sedang (lihat Tabel 3). Hal ini menunjukkan bahwa terhadap ketujuh indikator modal sosial tersebut, masyarakat nelayan di sekitar perairan Waduk Malahayu, Jawa Tengah menunjukkan kondisi yang cukup baik. Dalam kaitannya dengan mengefektfikan kelembagaan pemanfaatan dan pengelolaan sumberdaya perairan Waduk Malahayu, maka ketuju indikator modal sosial tersebut berpeluang untuk dapat ditingkat lebih baik lagi, yang tentunya dilakukan melalui berbagai upaya yang relevan dengan peningkatan ketujuh indikator modal sosial tersebut (Tabel 3)

\section{Perubahan Efektifitas Kelembagaan dan Peran Penguatan}

\section{Kapasitas Masyarakat di Waduk Malahayu}

Dalam penenltian ini, kelembagaan terkait dengan pengelolaan perikanan Waduk Malahayu, Kabupaten Brebes, Jawa Tengah terdiri dari tujuh jenis kelembagaan, yaitu: (1) Kelembagaan Pelaku Utama; (2) Kelembagaan Penyediaan sarana Produksi Perikanan; (3) Kelembagaan Pembinaan dan Penyuluhan; (4) Kelembagaan Konservasi; (5) Kelembagaan Pengawasan; (6) Kelembagaan Pemasaran Hasil Produksi Perikanan; dan (7) Kelembagaan Monitoring dan Evaluasi. Hasil assesment setiap jenis dan keseluruhan kelembagaan tersebut dijelaskan menurut sebaran kategori efektifitas dan dimensi aturan mainnya. Dalam hal ini aturan main yang digunakan sebagai ukuran efektifitas kelembagaan tersebut terdiri dari: (a) Prinsip Batas; (b) Distribusi Manfaat; (c) Pilihan Kolektif; (d) Kegiatan Memonitor; (e) Pemberian sanksi; (f) Mekanisme Penyelesaian Konflik; dan (g) Pengorganisasian Hak Kepemilikan (Ostrom, 1991). 
Tabel 3. Rata-Rata Skor dan Kategori Indikator Modal Sosial Nelayan di Periaran Waduk Malahayu. Jawa Tengah untuk Masing-masing dan Keseluruhan Indikator. 2011.

Table 3. Average of Score and Social Modal Indicators of Fisherman in Malahayu Reservoir. Central Java for Each and All Indicators. 2011.

\section{Indikator Modal Sosial/ \\ Social Modal Indicators}

1. Partisipasi sosial masyarakat di dalam komunitas (MDM1)/Social community participation in their community

2. Tingkat resiprositas dan proaktivitas di dalam kegiatan sosial (MDM2)/Level of reciprocity and proactivity on social activity

3. Perasaan Saling mempercayai dan rasa aman (MDM3)/ Mutual trust and sence of security

4. Jaringan dan koneksi dalam komunitas (MDM4)/Network and connection in community

5. Jaringan dan koneksi antar teman dan keluarga (MDM5)/Network and connection between friend and family

6. Toleransi dan kebhinekaan (MDM6)/ Tolerance and diversity

7. Nilai Hidup dan Kehidupan (MDM7)/ value of life and life

8. Koneksi/ jaringan kerja di luar komunitas (MDM8)/Connection/network outside community

9. Partisipasi dan keanggotaan kelompok di luar komunitas (MDM9)/Participation and memberofgroup outside community

$\begin{array}{llc}\text { Interval Skor/ } & \text { Skor/ } & \text { Ketgori/ } \\ \text { Score Interval } & \text { Score } & \text { Categories }\end{array}$

$5.00-20.00 \quad 14.13 \quad$ Sedang

$6.00-24.00$

17.40

Sedang

$10.00-40.00$

29.87

Sedang

$6.00-24.00$

17.90

Sedang

$5.00-20.00$

16.27

Tinggi

$5.00-20.00$

14.43

Sedang

$7.00-28.00$

23.17

Tinggi

$5.00-20.00$

14.10

Sedang

$5.00-20.00$

10.00

Sedang

\section{Keseluruhan Indikator Modal Sosial/ Total of Social Modal Indicators}

$49.00-216.00$

157.27

Sedang

Sumber: Data primer diolah (2011)/Source: Primary data processed.(2011)

Bila dilihat berdasarkan jenis kelembagaannya, peningkatan efektifitas kelembagaan tersebut tidak terjadi pada keseluruhan kelembagaan pengelolaan perikanan waduk, tetapi hanya pada empat dari tujuh jenis kelembagaan saja yang mengalami peruningkatan ke-fektifitassannya, yaitu: (1) Kelembagaan pelaku utama; (2) Kelembagaan pembinaan dan penyuluhan; (3) Kelembagaan konservasi; dan (4) Kelembagaan pengawasan. Empat kelembagaan ini mengamalami peningkatan dalam ke-efektif-annya, yaitu dari kategori cukup (sebelum penguatan kapasaitas masyarakat) menjadi efektif (setelah penguatan kapasitas masyarakat), secara rinci hal ini dapat dilihat pada Tabel 4. 
Tabel 4. Rataan Skor dan Kategori Efektivitas Kelembagaan Sebelum dan Setelah Penguatan Kapasitas Masyarakat di Waduk Malahayu, Jawa Tengah, 2011.

Table 4. Average of Score and Categories of Institutional Effectiveness Before and After Capacity Building of Community in Malahayu Reservoir, Central Java, 2011.

\begin{tabular}{|c|c|c|c|c|c|c|}
\hline \multirow{2}{*}{$\begin{array}{l}\text { Jenis Kelemba- } \\
\text { gaan/Type of } \\
\text { Institutional }\end{array}$} & \multicolumn{2}{|c|}{$\begin{array}{l}\text { Sebelum Penguatan/ } \\
\text { Before Capacity Building }\end{array}$} & \multicolumn{2}{|c|}{$\begin{array}{c}\text { Setelah Penguatan/ } \\
\text { After Capacity } \\
\text { Building }\end{array}$} & \multicolumn{2}{|c|}{ Perubahan/Change } \\
\hline & $\begin{array}{l}\text { Skor/ } \\
\text { Score }\end{array}$ & $\begin{array}{l}\text { Kategori/ } \\
\text { Categories }\end{array}$ & $\begin{array}{l}\text { Skor/ } \\
\text { Score }\end{array}$ & $\begin{array}{l}\text { Kategori/ } \\
\text { Categories }\end{array}$ & $\begin{array}{c}\text { Arah / } \\
\text { Direction }\end{array}$ & $\%$ \\
\hline $\begin{array}{l}\text { 1. Pelaku Utama/ } \\
\text { Person }\end{array}$ & 17.37 & $\begin{array}{l}\text { Cukup Efektif/ } \\
\text { Quite effective }\end{array}$ & 27.73 & $\begin{array}{l}\text { Efektif/ } \\
\text { Effective }\end{array}$ & $\begin{array}{l}\text { Meningkat/ } \\
\text { Increasing }\end{array}$ & 59.64 \\
\hline $\begin{array}{l}\text { 2. Saprokan/ } \\
\text { Production } \\
\text { facilities }\end{array}$ & 6.80 & $\begin{array}{l}\text { Tidak Efektif/ } \\
\text { Not effective }\end{array}$ & 6.80 & $\begin{array}{l}\text { Kurang } \\
\text { Efektif/ Less } \\
\text { Effective }\end{array}$ & $\begin{array}{l}\text { Tetap/ } \\
\text { Stagnan }\end{array}$ & 0.00 \\
\hline $\begin{array}{l}\text { 3. Penyuluhan/ } \\
\text { Counseling }\end{array}$ & 10.17 & $\begin{array}{l}\text { Cukup Efektif/ } \\
\text { Quite effective }\end{array}$ & 16.23 & $\begin{array}{l}\text { Efektf/ } \\
\text { Effective }\end{array}$ & $\begin{array}{l}\text { Meningkat/ } \\
\text { Increasing }\end{array}$ & 59.59 \\
\hline $\begin{array}{l}\text { 4. Konservasi/ } \\
\text { Concervation }\end{array}$ & 20.83 & $\begin{array}{l}\text { Cukup Efektif/ } \\
\text { Quite effective }\end{array}$ & 27.43 & $\begin{array}{l}\text { Efektif/ } \\
\text { Effective }\end{array}$ & $\begin{array}{l}\text { Meningkat/ } \\
\text { Increasing }\end{array}$ & 31.69 \\
\hline $\begin{array}{l}\text { 5. Pengawasan/ } \\
\text { Supervision }\end{array}$ & 24.73 & $\begin{array}{l}\text { Cukup Efektif/ } \\
\text { Quite effective }\end{array}$ & 33.27 & $\begin{array}{l}\text { Efektif/ } \\
\text { Effective } \\
\text { Kurang }\end{array}$ & $\begin{array}{l}\text { Meningkat/ } \\
\text { Increasing }\end{array}$ & 34.53 \\
\hline $\begin{array}{l}\text { 6. Pemasaran/ } \\
\text { Marketing }\end{array}$ & 7.97 & $\begin{array}{l}\text { Kurang Efektif/ } \\
\text { Less effective }\end{array}$ & 7.97 & $\begin{array}{l}\text { Efektif/ Less } \\
\text { effective }\end{array}$ & $\begin{array}{l}\text { Tetap/ } \\
\text { Stagnan }\end{array}$ & 0.00 \\
\hline $\begin{array}{l}\text { 7. Monev/ } \\
\text { Monitoring and } \\
\text { evaluation }\end{array}$ & 12.8 & $\begin{array}{l}\text { Kurang Efektif/ } \\
\text { Less effective }\end{array}$ & 12.8 & $\begin{array}{c}\text { Kurang } \\
\text { Efektif/ Less } \\
\text { effective }\end{array}$ & $\begin{array}{l}\text { Tetap/ } \\
\text { Stagnan }\end{array}$ & 0.00 \\
\hline Keseluruhan/ total & 100.67 & $\begin{array}{l}\text { Kurang Efektif/ } \\
\text { less effective }\end{array}$ & 132.23 & $\begin{array}{l}\text { Cukup efek- } \\
\text { tif/ Quite } \\
\text { effective }\end{array}$ & $\begin{array}{l}\text { Meningkat/ } \\
\text { Increasing }\end{array}$ & 31.35 \\
\hline
\end{tabular}

Sumber: Diolah dari data primer (2011)/Source: Primary data processed (2011)

Secara keseluruhan kondisi kelembagaan pengelolaan perikanan waduk Malahayu, Jawa Tengah setelah pelaksanaan program penguatan kapasitas masyarakat mengalami pergeseran (perubahan) yang meningkat pada tingkat efektifitasnya dibandingkan dengan kondisi sebelum program penguatan, yaitu dari dominasi kategori kurang efektif (sebelum penguatan) menjadi cukup efektif (setelah penguatan). Secara rinci, pergeseran (perubahan) efektifitas kelembagaan tersebut dapat dilihat pada Tabel 5.
Sementara untuk keseluruhan kelembagaan yang diamati, dari Tabel 5 diketahui bahwa rata-rata kelembagaan pengelolaan perikanan Waduk Malahayu, Jawa Tengah mengalami peningkatan efektifitas kelembagaan, yaitu dari kategori kurang efektif (sebelum penguatan kapasitas masyarakat)menjadi cukup efektif (setelah penguatan kapasaitas masyarakat). Hal ini menunjukkan adanya fakta bahwa program penguatan kapasitas masyarakat memberikan dampak yang positif bagi perubahan efektifitas kelembagaan pengelolaan perikanan Waduk Malahayu, Jawa Tengah yang meningkat. 
Tabel 5. Sebaran Kategori Efektifitas Kelembagaan Pengelolaan Perikanan Waduk Malahayu, Jawa Tengah pada Saat Sebelum dan Setelah Penguatan Kapasitas Masyarakat, 2011.

Table 5. Categories of Institutional Effectiveness Fisheries Management in Malahayu Reservoir, Central Java on Before and After Capacity Building of Community, 2011.

\begin{tabular}{lccccc}
\hline $\begin{array}{c}\text { Kategori } \\
\text { Efektifitas/ } \\
\begin{array}{l}\text { Categories of } \\
\text { Effectiveness }\end{array}\end{array}$ & $\begin{array}{c}\text { Interval Skor/ } \\
\text { Score Interval }\end{array}$ & $\begin{array}{c}\text { Sebelum } \\
\text { Penguatan/ } \\
\text { Before Capacity } \\
\text { Building (\%) }\end{array}$ & $\begin{array}{c}\text { Setelah } \\
\text { Penguatan/After } \\
\text { Capacity Building } \\
\text { (\%) }\end{array}$ & $\begin{array}{c}\text { Perubahan/ } \\
\text { Change } \\
\text { (\%) }\end{array}$ & $\begin{array}{c}\text { Keterangan/ } \\
\text { Remarks }\end{array}$ \\
\hline $\begin{array}{l}\text { Tidak Efektif/not } \\
\text { effective }\end{array}$ & $0.00-54.80$ & 0.00 & 0.00 & 0.00 & Tetap/stagnan \\
$\begin{array}{l}\text { Kurang Efektif/less } \\
\text { effective }\end{array}$ & $54.81-109.60$ & 63.33 & 10.00 & -53.33 & $\begin{array}{l}\text { Menurun/ } \\
\text { decreasing } \\
\text { Cukup Efektif/ quite } \\
\text { effective }\end{array}$ \\
$\begin{array}{l}\text { Efektif/ effective } \\
\text { Sangat Efektif/very } \\
\text { effective }\end{array}$ & $108.61-164.40$ & 36.33 & 90.00 & 53.33 & $\begin{array}{c}\text { Meningkat/ } \\
\text { increasing }\end{array}$ \\
\hline & $219.21-274.00$ & 0.00 & 0.00 & 0.00 & $\begin{array}{l}\text { Tetap/ stagnan } \\
\text { Tetap/ stagnan }\end{array}$ \\
\hline
\end{tabular}

Sumber: Diolah dari data primer (2011)/Source: primary data processed (2011)

Fakta tersebut juga didukung oleh hasil uji statistik non-parametrik dengan menggunakan pendekatan MannWhitney-U-Test menunjukkan bahwa secara statistik terdapat perbedaan yang sangat nyata (dengan arah sesuai yang diharapkan dan nilai z-hitung $=1.97$ pada taraf nyata $\alpha / 2=.0 .001$ ) antara rata-rata rank skor efektifitas kelembagaan pengelolaan waduk pada saat sebelum dilakukan penguatan masyarakat dengan rata-rata rank skor setelah dilakukan penguatan masyarakat.

Secara teoritis, fakta ini menunjukkan bahwa penguatan kapasitas masyarakat sebagai sebuah stimulus (rangsangan) telah mendapatkan respons masyarakat nelayan mengenai penguatan tersebut secara positif dan nyata sehingga diperoleh perubahan efektifitas kelembagaan pengelolaan perikanan Waduk Malahayu, Jawa Tengah yang lebih baik (meningkat) dibandingkan dengan sebelum dilakukan penguatan. Berdasarkan teori StimulusRespons (S-R), respon pada prosesnya didahului sikap seseorang, karena sikap merupakan kecenderungan atau kesediaan seseorang untuk bertingkah laku kalau ia menghadapi suatu stimulus (rangsangan) tertentu. Respon juga diartikan suatu tingkah laku atau sikap yang berwujud baik sebelum pemahaman yang mendetail, penilaian, pengaruh atau penolakan, suka atau tidak serta pemanfaatan pada suatu fenomena yang datang dari suatu stimulus (rangsangan) tertentu. (Fitts and Deininger, 2004; Proctor and Reeve, 2009).

Hubungan antara Modal Sosial dan Respons Masyarakat dengan Perubahan Efektifitas Kelembagaan Pengelolaan Perikanan Waduk

Hasil pengujian statistis korelasi pearson product moment (PPM) antara peubah modal sosial masyartakat (MDM) dan peubah respons masyarakat mengenai penguatan kapasitas (RSP) peubah perubahan efektifitas kelembagaan pengeloaan perikanan Waduk Malahayu (PEK) secara rinci ditunjukkan dalam Tabel 6.

Dari hasil pengujian tersebut (Tabel 6) ditemukan bahwa terdapat hubungan dengan arah postif yang nyata antara peubah modal sosial masyarakat (MDM) dengan respons masyarakat mengenai program penguatan kapasitas kelembagaan masyarakat (RSP). 
Tabel 6. Hasil Pengujian Korelasi antar Peubah Penelitian Respons Masyarakat, Modal Sosial dan Perubahan Efektifitas Kelembagaan Pengelolaan Perikanan Waduk Malahayu, Jawa Tengah, 2011.

Table 6. The Result of Correlation Among Community Respons, Social Modal and Change ff Institutional Effectiveness Fisheries Management In Reservoir Malahayu, Central Java, 2011.

\begin{tabular}{lcc}
\hline $\begin{array}{c}\text { Hubungan antar Peubah Penelitian/ } \\
\text { Relationship between variables }\end{array}$ & $\begin{array}{c}\text { Nilai Hitung Koefisien Kore- } \\
\text { lasi Pearson/coefficient value } \\
\text { of Pearson Correlation }\end{array}$ & Sig. (2-tailed) \\
\hline $\begin{array}{l}\text { 2. Respons Masyarakat (RSP) - Modal } \\
\text { Sosial (MDM)/Community respons- } \\
\text { social modal }\end{array}$ & $0.521^{* *}$ & 0.003 \\
$\begin{array}{l}\text { 1. Respons Masyarakat (RSP) - } \\
\text { Perubahan Efektifitas Kelembagaan } \\
\begin{array}{l}\text { (PEK)/Community respons-change of } \\
\text { institutional effectiveness }\end{array}\end{array}$ & \\
\hline
\end{tabular}

Sumber: Hasil Pengujian menggunakan Sofware SPSS 16.0 (2011)

Keterangan: $* * *=$ korelasi sangat nyata pada taraf $\alpha / 2=0,001$

$* *=$ korelasi cukup nyata pada taraf $\alpha / 2=0,001$

$*$ = korelasi kurang nyata pada taraf $\alpha / 2=0,05$

Source: Result of research using software SPSS 16.0 (2011)

Remarks: : $* * *=$ more significant correlation on level $\alpha / 2=0,001$

** = significant correlation on level $\alpha / 2=0,001$

$*$ = less significant correlation on level $\alpha / 2=0,05$

Hal ini berarti bahwa semakin tinggi modal sosial masyarakat (MDM) akan mendorong respons masyarakat (RSP) mengenai program penguatan kapasitas masyarakat (RSP). Selanjutnya, ditemukan pula terdapat hubungan dengan arah postif yang nyata antara perubah respons masyarakat (RSP) mengenai penguatan kapasitas masyarakat dengan peubah perubahan efektifitas kelembagaan waduk (PEK).

Dengan demikian, berdasarkan hasil pengujian hubungan antar peubah penelitian tersebut di atas (Tabel 7) diketahui bahwa peubah modal sosial masyarakat (MDM) memiliki peran penting sebagai peubah penjelas (explanatory variable) atau faktor yang mendorong perubahan respon masyarakat (RSP). Sedangkan peubah RSP itu sendiri menjelaskan hubungan nya yang positif terhadap peubah efektifitas kelembagaan.

Hal ini mengindikasikan bahwa peubah modal sosial masyarakat (MDM) memiliki kedudukan penting dalam menentukan keberhasilan penguatan kapasitas yang direspons masyarakat untuk menghasilkan perubahan yang meningkat pada efektifitas kelembagaan pengelolaan Waduk Malahayu, Jawa Tengah.

Selanjutnya, untuk mengetahui lebih detail indikator-indikator manakah dari peubah modal sosial (mulai MDM1 hingga MDM9) yang secara nyata berperan penting sebagai penjelas dalam hubungan antara tingkat respons masyarakat mengenai penguatan kapasitas kelembagaan pengelolaan perikanan Waduk Malahayu, Jawa Tengah dilakukan pengujian korelasi lanjutan sebagaimana tertera pada Tabel 7.

Berdasarkan hasil pengujian korelasi pearson antara peubah respons masyarakat mengenai penguatan kapasitas masyarakat (RSP) dengan peubah-peubah indikator modal sosial (MDM1 sampai dengan MDM9), sebagaimana tertera pada Tabel 6 dan Gambar 4 diketahui bahwa respons masyarakat mengenai penguatan kapasitas (RSP) berhubungan positif dan sangat 
nyata dengan tiga indikator modal sosial masyarakat, yaitu: indikator perasaan saling mempercayai dan rasa aman (MDM3), indikator toleransi dan kebhinekaan (MDM6), dan in indikator nilai hidup dan kehidupan (MDM8). Selanjutnya, hubungan respons masyarakat (RSP) dengan indikator jaringan dan koneksi di dalam komunitas (MDM4), indikator jaringan dan koneksi antar teman dan keluarga (MDM5), indikator jaringan koneksi di luar komunitas (MDM7), dan partisipasi dan keanggotaan kelompok di luar komunitas (MDM9) berhubungan positif namun hanya pada taraf cukup nyata. Sementara dengan dua indikator dari modal sosial lainnya, yaitu indikator partisipasi dan keanggotaan kelompok di dalam komunitas (MDM1) dan indikator tingkat reprositas dan proaktivitas di dalam kegiatan sosial (MDM2), peubah respons masyarakat mengenai penguatan kapasitas (RSP) tidak menunjukan hubungan yang nyata meskipun masih memberikan arah yang positif.

Tabel 7. Hasil Pengujian Korelasi antara Peubah Indikatorr Modal Sosial dengan Peubah Respons Masyarakat Nelayan Waduk Malahayu, Jawa Tengah, 2011.

Table 7. Result of Correlation Between Social Modal and Fisheries Community Respons in Malahayu Reservoir, Central Java, 2011.

Indikator Modal Sosial (MDM)/ Social Modal Indicators
Respons Masyarakat Nelayan (RSP)/

Fisheries Community Respons

Koefisien r-pearson

Sig. (2-tailed)

1. Partisipasi sosial masyarakat di dalam komunitas (MDM1)/ Social community participation in their community

2. Tingkat resiprositas dan proaktivitas di dalam kegiatan sosial (MDM2)/ Level of reciprocity and proactivity on social activity

3. Perasaan saling mempercayai dan rasa aman (MDM3)/ Mutual trust and sence of security

4. Jaringan/ koneksi dalam komunitas (MDM4)/ Network and connection in community

5. Jaringan dan koneksi antar teman dan 0.153 0.418 keluarga (MDM5)/ Network and connection between friend and family

6. Toleransi dan kebhinekaan (MDM6)/ 0.069 Tolerance and diversity

7. Jaringan/koneksi di luar komunitas (MDM7)/ Connection/network outside community

8. Nilai hidup dan kehidupan (MDM8)/ Value of life and life

9. Partisipasi dan keanggotaan kelompok di luar Komunitas (MDM9)/ Participation and member of group outside community

Sumber: Hasil Pengujian menggunakan Sofware SPSS 16.0 (2011)

Keterangan: ${ }^{* * *}=$ korelasi sangat nyata pada taraf $\alpha / 2=0,001$

$* *$ = korelasi cukup nyata pada taraf $\alpha / 2=0,01$

$*$ = korelasi kurang nyata pada taraf $\alpha / 2=0,05$

Source: Result of research using software SPSS 16.0 (2011)

Remarks: : $\quad * * *=$ more significant correlation on level $\alpha / 2=0,001$

$* *$ significant correlation on level $\alpha / 2=0,001$

$*$ = less significant correlation on level $\alpha / 2=0,05$

\subsection{3}

0.009

0.043

0.008

0.034 


\section{KESIMPULAN DAN IMPLIKASI KEBIJAKAN}

\section{Kesimpulan}

Penguatan kapasitas masyarakat memiliki peran yang positif dan nyata terhadap perubahan efektifitas kelembagaan terkait pengelolaan perikanan Waduk Malahayu, Jawa Tengah yang meningkat. Respons masyarakat mengenai penguatan kapasitas masyarakat berhubungan positif dan cukup nyata dengan perubahan efektifitas kelembagaan tersebut, yang dijelaskan oleh peubah modal sosial masyarakatnya. Respons masyarakat mengenai penguatan kapasitas (RSP) berhubungan positif dan sangat nyata dengan tiga indikator modal sosial masyarakat, yaitu: indikator perasaan saling mempercayai dan rasa aman (MDM3), indikator toleransi dan kebhinekaan (MDM6), dan in indikator nilai hidup dan kehidupan (MDM8).

\section{Implikasi Kebijakan}

Sebagaimana ditunjukkan dari hasil penelitian ini, adanya kecenderungan yang mengindikasikan pentingnya faktor modal sosial dalam menjelaskan keberhasilan program penguatan kapasitas yang direspons oleh masyarakat dalam meningkatkan efektifitas kelembagaan pengelolaan perikanan Waduk Malahayu, Jawa Tengah. Temuan tersebut juga menunjukkan perlunya memupuk perasaan saling mempercayai dan rasa aman, toleransi dan kebhinekaan, dan nilai hidup dan kehidupan sebagai bagian dari upaya rekayasa sosial (social enginering), khususnya dalam upaya meningkatkan efektifitas kelembagaan pengelolaan perikanan waduk yang memberikan jaminan keberlanjutannya. Upaya tersebut juga perlu ditunjang dengan kegiatan-kegiatan yang dapat meningkatkan jaringan dan koneksi di dalam komunitas, jaringan dan koneksi antar teman dan keluarga, jaringan koneksi di luar komunitas, dan partisipasi dan keanggotaan kelompok di luar komunitas, sehinga ketiga jaringan dan koneksi tersebut dapat menjadi semakin intens dan luas, demikian pula dengan partisipasi di luar komunitas.

\section{DAFTAR PUSTAKA}

Bodgan, R. and Taylor, S.J. 2000. Introduction to Qualitative Research Methods. New York. John Willey.

BPS. 2006. Tingkat Kemiskinan di Indonesia. Berita Resmi Statistik No. 47/X/1 September 2006.

Collen, M. and Whiteford, H. 2001. The Interrealations of Social Capital with Health and Mental Health. Discussion paper. Mental Health and Social Program Branch Commonwealth. Department of Health and Agent Care. Canberra. The Commonwealth Australia.

Embretson, S., and Reise, S. 2000. Item Response Theory for Psychologists. Mahwah, NJ: Lawrence Ehrlbaum Associates.

Fitts, P. M., and Deininger, R. L. 2004. Stimulus-Respons (S-R) Compatibility: Correspondence among paired elements within stimulus and response codes. Journal of Experimental Psychology, 48, 483-493.

Fukuyama, F. 2002. The Great Descriptrion: Isu, Sintesis dan Gagasan. Gramedia Pustaka Utama. Jakarta.

Green, S. B., \& Salkind, N. J. 2008.. Using SPSS for Window and Macintosh: Analyzing and understanding data (5th ed.). Upper Saddle River, NJ: Pearson Prentice Hall.

Hasbullah, F. 2006. Social Capital: Menuju Keunggulan Budaya Manusia Indonesia. MR-United Press, Jakarta.

Juanda, B. 2009. Metodologi Penelitian Ekonomi dan Bisnis. Edisi Kedua. IPB Press, Bogor. Hal. 109-122.

Kemalasari. 2005. Tingkat Kesejahteraan Rumah Tangga Nelayan Migran di Desa Penimbang, Kecamatan Panimbang, Kabupaten Pandeglang, provinsi Jawa Barat. Skripsi. Program Studi Manajemen Bisnis dan Ekonomi 
Perikanan-Kelautan. Fakultas Perikanan dan Ilmu Kelautan. Institut Pertanian Bogor.

Lenggono, P.S. 2004. Modal Sosial dalam Pengelolaan Tambak: Studi Kasus pada Komunitas Petambak di Desa Muara Pantuan, Kecamatan Anggana, Kabupaten Kutai Kertanegara. Tesis. Sekolah Pascasarjana. Fakultas Perikanan dan Ilmu Kelautan. Institut Pertanian Bogor.

Menkokesra. 2005. Strategi Penanggulangan Kemiskinan Nasional. Tim Koordinasi Penyiapan Penyusunan Perumusan Kebijakan Penanggulangan Kemiskinan. Bidang Koordinasi Penanggulangan Kemiskinan.

Ostrom, E., 1990. Governing the Commons: the evolution of institutions for collective action. Cambridge University Press. New York.

Proctor, R.W. and Reeve, T.G. 2009. Stimulusresponse compatibility: An integrated perspective. Amsterdam: North-Holland. Pp. 3-30.
Reuben M. B., and David A. K. 2006. The Moderator-Mediator Variable Distinction in Social Psychological Research: Conceptual, Strategic and Statistical Considerations. Journal of Personality and Social Psychology. Vol. 51, No. 6, 1173-1182.

Satria, A. 2009 . Menyimak Nasib Nelayan, Republika Ahad 1 Nopember 2009, Dari Ekologi Politik Nelayan, Penerbit LKIS, Yogyakarata.

Siegel, S. 1998. Non Parametric Statistics for the Behavioural Sciences. Second Edition McGraw-Hill. The University of Michigan. $312 \mathrm{p}$.

Singarimbun, M, dan Effendi, S. 1998. Metode Penelitian Survai, Jakarta, LP3ES.

Sprent, P. and Smeecon, N.C. 2001. Applied Non Parametric Statistics Methods. Third Edition. Vahapman \& Hall/CRS. 461 p.

Strauss, S. dan J. Corbin. 2003. Dasar-Dasar Penelitian Kualitatif. Tatalangkan dan Teknik-Teknik Teorisasi Data. Pustaka Pelajar Yogyakarta. 